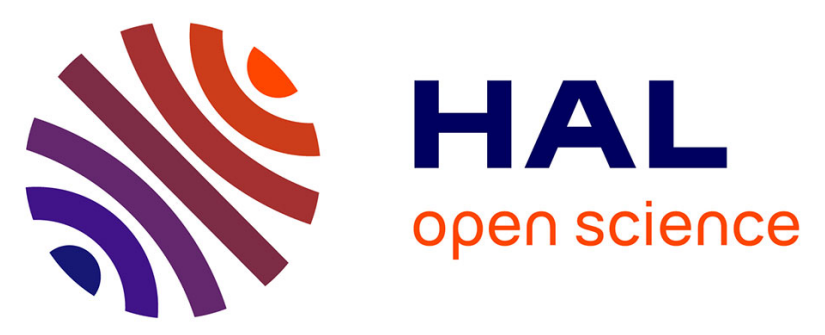

\title{
Stainless steel fibre reinforced aluminium matrix composites processed by squeeze casting: relationship between processing conditions and interfacial microstructure
}

\author{
C. Colin, Y. Marchal, F. Boland, F. Delannay
}

\section{To cite this version:}

C. Colin, Y. Marchal, F. Boland, F. Delannay. Stainless steel fibre reinforced aluminium matrix composites processed by squeeze casting: relationship between processing conditions and interfacial microstructure. Journal de Physique IV Proceedings, 1993, 03 (C7), pp.C7-1749-C7-1752. 10.1051/jp4:19937276 . jpa-00251917

\section{HAL Id: jpa-00251917 https://hal.science/jpa-00251917}

Submitted on 1 Jan 1993

HAL is a multi-disciplinary open access archive for the deposit and dissemination of scientific research documents, whether they are published or not. The documents may come from teaching and research institutions in France or abroad, or from public or private research centers.
L'archive ouverte pluridisciplinaire HAL, est destinée au dépôt et à la diffusion de documents scientifiques de niveau recherche, publiés ou non, émanant des établissements d'enseignement et de recherche français ou étrangers, des laboratoires publics ou privés. 


\title{
Stainless steel fibre reinforced aluminium matrix composites processed by squeeze casting: relationship between processing conditions and interfacial microstructure
}

\author{
C. COLIN ${ }^{(1)}$, Y. MARCHAL, F. BOLAND and F. DELANNAY \\ Université Catholique de Louvain, Département des Sciences des Matériaux et des Procédés, PCIM, Place \\ Sainte Barbe 2, 1348 Louvain-la-Neuve, Belgium
}

\begin{abstract}
This work investigates the influence of some processing parameters on the extent of interfacial reaction in squeeze cast aluminium matrix composites reinforced with $12 \mu \mathrm{m}$ diameter, continuous stainless steel fibres. The average thickness of the reaction layer at fibre/matrix interfaces was measured by image analysis. When casting was made in a die at room temperature, the thickness of the reaction layer was affected on a distance of several $\mathrm{mm}$ from the lateral surface or from the bottom of the preform. The results indicate that the major part of the reaction occurs before solidification of the liquid metal. The control of the extent of interfacial reaction can be achieved through optimization of both infiltration parameters and features of the preform such as the volume fraction of the fibres.
\end{abstract}

\section{INTRODUCTION}

A drastic enhancement of the creep properties of low melting point alloys can be obtained by reinforcing these alloys with continuous fibres of a more refractory material[1,2]. Little attempt has been made up to now to use metallic fibres for strengthening aluminium alloys because of the high reactivity of aluminium with most metallic fibres. This paper aims at studying some parameters affecting the extent of reaction between aluminium and stainless steel fibres $316 \mathrm{~L}$ in composites processed by squeeze casting. These perameters are the volume fraction of the fibres, the temperature of the liquid metal at the time of casting, and the preheating temperatures of the die and of the preform.

\section{EXPERIMENTAL}

The squeeze casting set-up is presented in figure 1 and it has been described by several research workers [3-5]. Use is made of a cylindrical die with a diameter of $95 \mathrm{~mm}$. The fibre preforms deposited in the die were $10 \mathrm{~mm}$ thick mats containing $20 \mathrm{vol} \%$ of $316 \mathrm{~L}$ austenitic stainless steel fibres with a diameter of 12 $\mu \mathrm{m}$ (N.V. Bekaert S.A.). These mats have been consolidated by sintering. The fibres orientation was isotropic in the plane of the mats. A weight of $450 \mathrm{~g}$. of pure aluminium $(99.99 \%)$ was heated at a casting temperature varying between 750 and $950^{\circ} \mathrm{C}$. Immediately after pouring the metal on the upper surface (70 $x 50 \mathrm{~mm}^{2}$ ) of the preform, a punch applied a pressure of $20 \mathrm{MPa}$ on the liquid in such a way as to force the infiltration of the preform. The temperature of both die and preform at the time of infiltration was either $25^{\circ} \mathrm{C}$ or $250^{\circ} \mathrm{C}$ whereas the temperature of the punch was always $25^{\circ} \mathrm{C}$.

The castings were cut into $8 \mathrm{~mm}$ thick slices by sawing in such a way as to allow the investigation of the distribution of the microstructure from the sides to the center of the infiltrated preform. The different slices were polished and observed by scanning electron microscopy using backscattered electrons in order to reveal the different phases. (The higher the average atomic weight of the phases, the brighter the contrast on the images). The composition of these phases was determined by electron probe microanalysis (EPMA) whereas their surface area was measured by computerized image analysis. 


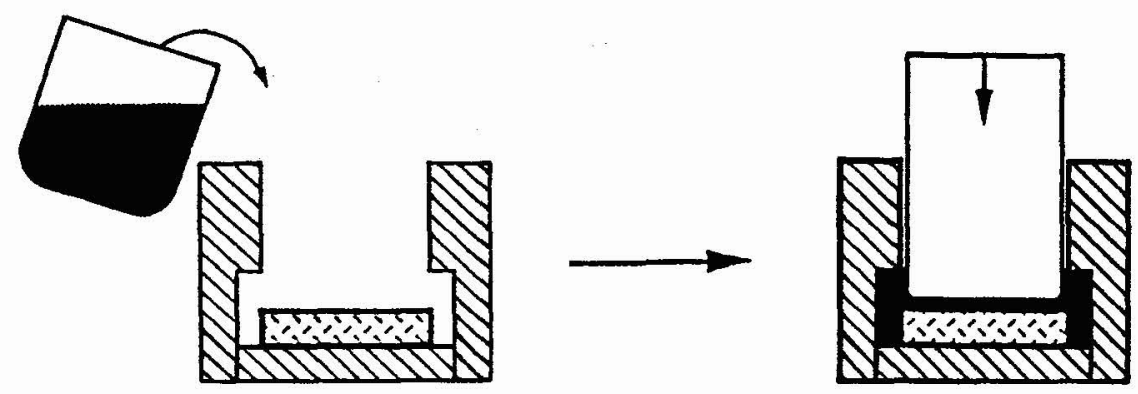

Figure 1 : Squeeze casting set-up

\section{RESULTS}

Figure 2 illustrates the typical microstructure observed in the center of the preform. As a result of the reaction at fibre/matrix interfaces, one notices (i) the formation of a ring of intermetallic compounds around the fibres, (ii) the precipitation of large elongated crystalline particles, and (iii) the presence of an eutectic phase decorating the dendrites in the Al matrix. EPMA indicated that the rings contain mainly the binary intermetallic compounds $\mathrm{Fe}_{2} \mathrm{Al}_{5}$ or $\mathrm{FeAl}_{3}$ with some solid solutions of $\mathrm{Ni}$ and $\mathrm{Cr}$, as already revealed by R.B. Bhagat $[6,7]$. The large crystalline precipitates are essentially ternary compounds containing about $70 \mathrm{wt} \% \mathrm{Al}, 16 \mathrm{wt} \% \mathrm{Cr}$ and $12 \mathrm{wt} \% \mathrm{Fe}$. The eutectic phase is mainly consisted of the binary eutectic Al-Fe.

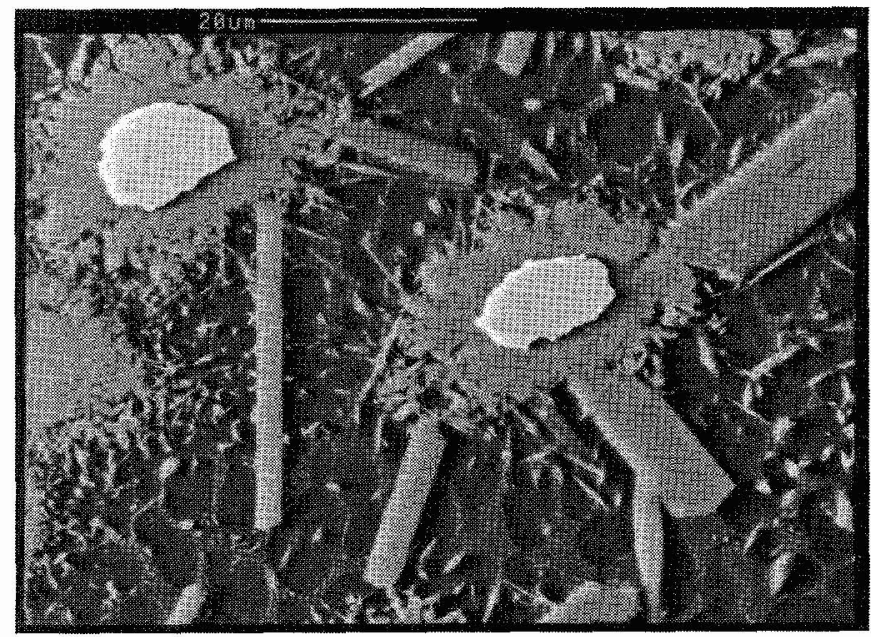

Figure 2 : Microstructure of a pure $\mathrm{Al}$ matrix composite reinforced with stainless steel (316L) fibres. The two main features resulting from the reaction at fibre/matrix interfaces are the formation of a ring of intermetallic compounds around the fibres together with the precipitation of elongated crystalline particles

The amount of reaction was quantified by image analysis by measuring on a set of images the average thickness $X$ of the intermetallic rings around the fibres using the relation :

$$
X=\sqrt{\frac{S_{f}+S_{i}}{n \pi}}-\sqrt{\frac{S_{f}}{n \pi}}
$$

where $S_{f}$ is the surface area of fibres, $S_{i}$ is the surface area of the intermetallic compounds and $n$ is the number of fibres. 
Figure 3 presents, for 3 castings processed under different conditions, the variation of the average thickness of the intermetallic rings as a function of the distance from the sides of the preform (i.e. close to the die wall) along a radius in the mid-plane of the casting and along the axis of the casting from the bottom of the die. The numbers $\mathrm{xxx} / \mathrm{xxx}$ refer successively to the temperature of the liquid and the temperature of the die and preform (e.g. 750/250 designates a sample processed using a casting temperature of $750^{\circ} \mathrm{C}$ and a die and preform preheated at $250^{\circ} \mathrm{C}$ ). In each case, the minimum amount of intermetallics is observed at the bottom of the preform in contact with the die and the maximum at the top of the preform where the liquid metal has been poured. The influence of the die temperature appears larger than the influence of the liquid temperature. A large gradient along both the radius at mid-plane and the axis of the preform is observed after casting in a die at room temperature.

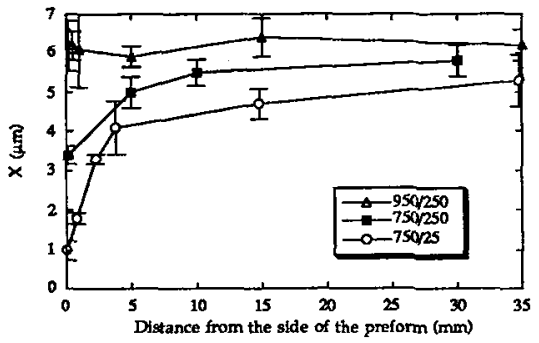

a

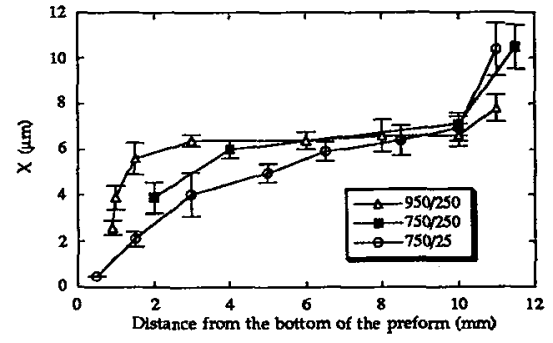

b

Figure 3 : Variation of the average thickness of the intermetallic rings around the fibres as a function of the distance from the sides of the preform (i.e. close to the die wall) : (a) along a radius in the mid-plane of the casting; (b) along the axis of the casting from the bottom of the die. (The numbers refer successively to the temperature of the liquid and the temperature of the die and preform).

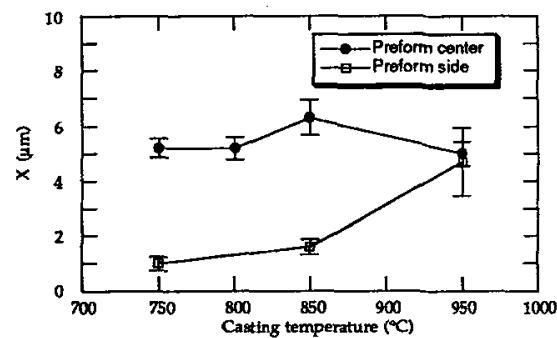

a

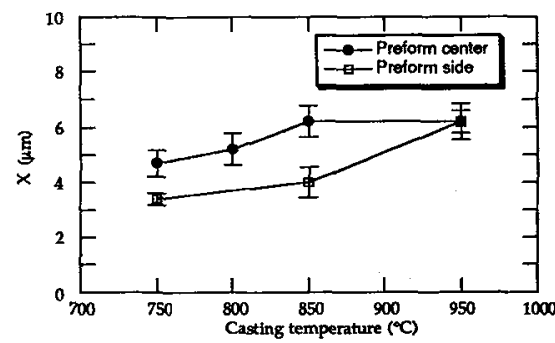

b

Figure 4: Average thickness of the intermetallic rings around the fibres at two points on the longitudinal axis of the casting $-r=35, z=5 \mathrm{~mm}$ (side) and $r=0, z=5 \mathrm{~mm}$ (center) - as a function of the temperature of the liquid at the time of infiltration. (a) after casting with die and preform at room temperature. (b) after casting with die and preform preheated at $250^{\circ} \mathrm{C}$

Figure 4 presents the average thickness of the intermetallic rings on the longitudinal axis at the side and at the center of the preform as a function of the casting temperature in the cases of a die and preform maintained at room temperature and of a die and preform preheated at $250^{\circ} \mathrm{C}$. This figure illustrates clearly the large gradients of reaction obtained when the casting occurs in a die at room temperature.

As a complement to these investigations, bulk pieces of stainless steel $316 \mathrm{~L}$ have, in some instances, been placed in the die together with the preform before the casting of the metal. In no case, any significant amount of intermetallic compounds was detected at the interface between the aluminium matrix and these pieces after solidification. 


\section{DISCUSSION AND CONCLUSION}

The results may be interpreted by considering that the intermetallic compounds form essentially during the time of contact of the fibres with the liquid metal. Hence, the areas containing less intermetallic compounds correspond to the areas where the solidification rate is higher and/or where the infiltration occurs later. The location of these areas depends on the processing conditions, namely : temperature of the liquid metal before the infiltration and preheating temperature of the die and of the preform.

The intermetallic gradients observed through the preform of fibres (figure 3 ) allow to idendificate three regions where the durations of the solidification dwell (located to $660^{\circ} \mathrm{C}$ for pure $\mathrm{Al}$ ) are differents. The maximum layer thickness (about $10 \mu \mathrm{m}$ ) is measured on the upper and median surface of the preform where is poured the liquid metal (region 1). To the center of the preform (region 2) is observed an uniform reaction layer between the fibres and the matrix, characterized by intermetallic plateaux. The extent of these plateaux (i.e. the size of the region 2) depends on the amount of the liquid volume and on its spreading on the top of the preform before applying the pressure. The higher the die and casting temperatures, the greater the length of the plateau. In this region, the infiltration seems to be adiabatic and unidirectional. On the other hand, a changing the casting temperature has no significant effect on the reaction layer thickness because the solidification dwell time is not much modified. The average layer thickness measured by image analysis amounts to 5-6 $\mu \mathrm{m}$. An important cooling rate of the preform, close to the die wall, leads to the formation of a region 3, characterized by a low reaction layer thickness. Usually, in this region of the preform develops a temperature gradient bringing about an intermetallic gradient. This last one disappears progressively with increasing the preheating temperature of the die. Indeed by using a hot die, the infiltration becomes isotropic owing to the injection of liquid metal from the lateral sides in addition to the top of the preform. A similar mechanism of the infiltration of liquid pure metal into a preform has already been described by A. Mortensen and co-workers, from both theoretical [8] and experimental [9] standpoints.

In addition, the fact that no intermetallic is found at the interface with a bulk stainless steel piece is due to the high heat extraction of such a bulk piece, which allows very rapid solidification at the interface. So, it is concluded that the factor most strongly influencing reaction layer thickness is the solidification rate of liquid metal around the fibres. Therefore, the volume fraction of the fibres is expected to have a significant effect on the formation and the growth of the intermetallic compounds. The higher the volume fraction of the fibres, the lower the chemical reaction of pure $\mathrm{Al}$ in contact with fibres.

\section{ACKNOWLEDGEMENTS}

The fibres used in this work were supplied by the company N.V. Bekaert S.A.. This work was carried out under financial support of the Ministry of Research and Technologies of the Walloon Region (Belgium).

\section{REFERENCES}

[1] M.A. Dellis, H. Schobbens, M. Van den Neste, B. Lips, J. Wégria and F. Delannay, in "Metal Matrix Composites-Processing, Microstructure and Properties", Ed. by N. Hansen, D. Juul Jensen, T. Leffers, H. Lilholt, T. Lorentzen, A.S. Pedersen, O.B. Pedersen and B. Ralph, Ris $\varnothing$ National Laboratory, Roskilde, Denmark, 1991, pp. 299-304.

[2] M.A. Dellis, J.P. Keustermans, J. Wégria and F. Delannay, Materials Science and Engineering, A 135, 1991, pp 253-257.

[3] A. Mortensen, J.A. Cornie and M.C. Flemings, 5th annual Conference on Materials Technology, Carbondale Ilinois USA, 14-15 April 1988, pp 3-31.

[4] S. Nagata and M. Sakamoto, Materials and Design, Vol. 10, No 3, May/June 1989, pp 153-158.

[5] F.A. Girot, R. Fédou, J.M. Quenisset and R. Naslain, Journal of Reinforced Plastics and Composites, Vol. 9, September 1990, pp 456-469.

[6] R.B. Bhagat, Composites, Vol. 19, N 5, September 1988, pp393-399.

[7] R.B. Bhagat, Journal of Materials Science, Vol. 24, 1989, pp 1496-1502.

[81 A. Mortensen, L.J. Masur, J.A.Cornie and M.C. Flemings, Metallurgical Transactions A, Vol. 20 A, November 1989, pp 2535-2547.

[9] L.J. Masur, A. Mortensen, J.A. Cornie and M.C. Flemings, Metallurgical Transactions A, Vol.20A, November 1989, pp 2549-2557. 